This PDF is a selection from a published volume from the National Bureau of Economic Research

Volume Title: Health Care Issues in the United States and Japan

Volume Author/Editor: David A. Wise and Naohiro Yashiro, editors

Volume Publisher: University of Chicago Press

Volume ISBN: 0-262-90292-7

Volume URL: http://www.nber.org/books/wise06-1

Conference Date: May 1-3, 2003

Publication Date: September 2006

Title: The U.S. Medical Care System for the Elderly

Author: David M. Cutler, David A. Wise

URL: http://www.nber.org/chapters/c7359 


\section{The U.S. Medical Care System for the Elderly}

David M. Cutler and David A. Wise

This paper examines the structure of the American medical care system, focusing primarily on the system of care for the elderly. Understanding the design of medical care systems is important for several reasons. First, we frequently want to know how to compare systems across countries. Is the American medical care system closer to the European model or the Japanese model? How different are the medical systems across continental European countries? To answer these questions, we need to characterize the systems themselves.

We are also interested in medical system structure because we want to relate structures to outcomes. Is the longer life expectancy in Japan than in the United States attributable to the Japanese medical system, or to other factors? Which country has the better medical care system? Understanding how medical systems work is the key to starting.

Medical care systems are multidimensional, and so our description must be as well. The basis for our analysis is the medical care triad, presented in figure 2.1.' There are three participants in the medical care system: pa-

David M. Cutler is the Otto Eckstein Professor of Applied Economics, Department of Economics and John F. Kennedy School of Government, and social sciences dean in the Faculty of Arts and Sciences, both at Harvard University, and a research associate of the National Bureau of Economic Research. David A. Wise is the John F. Stambaugh Professor of Political Economy at the John F. Kennedy School of Government, Harvard University, and director of the Program on Aging at the National Bureau of Economic Research.

We are grateful to the National Institutes of Health for research support through grants P01-AG05842 and P30-AG012810 and to participants at the NBER-JCER Conference on Health Care in the United States and Japan for comments.

1. Figure 2.1 is not new to us. The distinction between coverage, reimbursement, and access is common in the literature. See, for example, Reinhardt (2004), Evans (2002), and Chernichovsky (1995). 


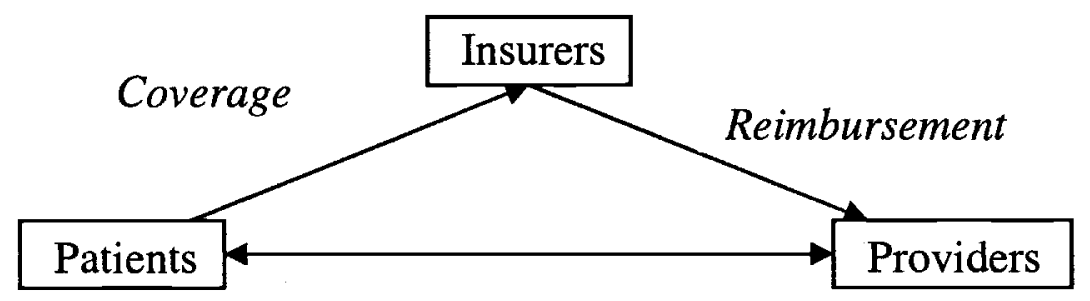

Access

Fig. 2.1 The medical care triad

tients, providers, and insurers. Patients pay money to insurers (either directly or indirectly, as we discuss in the following) and pay for some care directly. Insurers reimburse providers for care and set rules under which the care can be provided. Providers diagnose and treat patients.

Corresponding to these three participants are three sets of interactions. The first is the coverage rules. This encompasses the mechanisms by which people get health insurance and who pays for that insurance. The second interaction is the reimbursement system between insurers and providershow is payment determined and what rates are paid? Finally, there are the access rules - which providers are patients allowed to see and under what circumstances? In this paper, we describe the insurance, reimbursement, and access rules in the American medical care system. The paper can be compared with the work of Yashiro, Suzuki, and Suzuki (chap. 1 in this volume), who analyze the Japanese medical system in a similar framework. We present broad outlines of the system for everyone in the United States. Because the system is so heterogeneous, we focus particular attention on the system for the elderly. We note where research has explored a link between system provisions and outcomes, but we do not take the further step of relating system provisions to health outcomes in any systematic way.

We begin in section 2.1 by presenting a brief overview of medical systems in developed countries. We show the large differences in medical spending and health outcomes across countries that motivate our desire to make system comparisons. Section 2.2 discusses the methods through which Americans get insurance coverage and the flow of money. Section 2.3 highlights the reimbursement arrangements that providers operate under, and section 2.4 presents the access rules for patients and providers. We end with a brief conclusion.

\subsection{The International Experience}

The performance of medical care systems differs enormously across countries. To give a summary of this performance, we emphasize two di- 
mensions most relevant for economic analysis: how much the system costs and how healthy people are, perhaps as a result of the medical system. ${ }^{2}$

To measure costs, we look at medical spending as a share of gross domestic product (GDP). Gross domestic product is a natural scalar by which to evaluate medical care; a richer country should spend more on medical care than a poorer country. In principle, a more accurate scalar would be the amount of medical spending that is expected, given the income elasticity of medical care. That elasticity is not known, however. In microdata, the elasticity of medical spending with respect to income is far below 1 , generally about .2 (Newhouse 1993). This suggests that we should look at per capita spending more than spending relative to GDP. This comparison, however, presumes that prices are constant across countries at a point in time. In fact, medical prices rise with income (Baumol 1967). In macroregressions, the income elasticity is usually somewhat above 1 (Getzen 2000). But that is likely overstated, as it reflects demand as well as technology conditions. There is no obvious scalar, so we focus on the GDP comparison.

Figure 2.2 shows medical spending as a share of GDP in Organization for Economic Cooperation and Development (OECD) countries. The data are for 1998, the most recent year in which they are complete. The United States spends the most of any country on medical care, nearly 14 percent of GDP. The next highest country, Switzerland, spends only 11 percent of GDP on medical care. Among high income countries, the United Kingdom is a very low outlier, spending only 7 percent of GDP on medical care. The average in the OECD is about 8 percent.

To measure health, we use life expectancy at birth. Life expectancy is the most common summary of health in the literature. In using this indicator, we emphasize immediately that it is influenced by far more than medical care. Life expectancy is affected by lifestyle factors (smoking, diets), environmental conditions (air pollution), and other economic and social factors. Our purpose here is not to grade medical systems. Rather, we want to illustrate the range of variation in the data.

Life expectancy in OECD countries is shown in figure 2.3. Once again, there is wide variation. The mean across developed countries is seventyseven years. The United States, although with a life expectancy of seventyseven years (equal to the mean), ranks twenty-first of the thirty countries shown in the figure. Japan is the clear positive outlier, with life expectancy of eighty-one years.

Comparing figures 2.2 and 2.3 suggests little correlation between medical spending and life expectancy. Figure 2.4 shows this explicitly. The hor-

2. Other dimensions of performance include the degree to which the system treats people fairly and the extent to which it upholds normative values of right and wrong. We are less able to measure these dimensions quantitatively. 


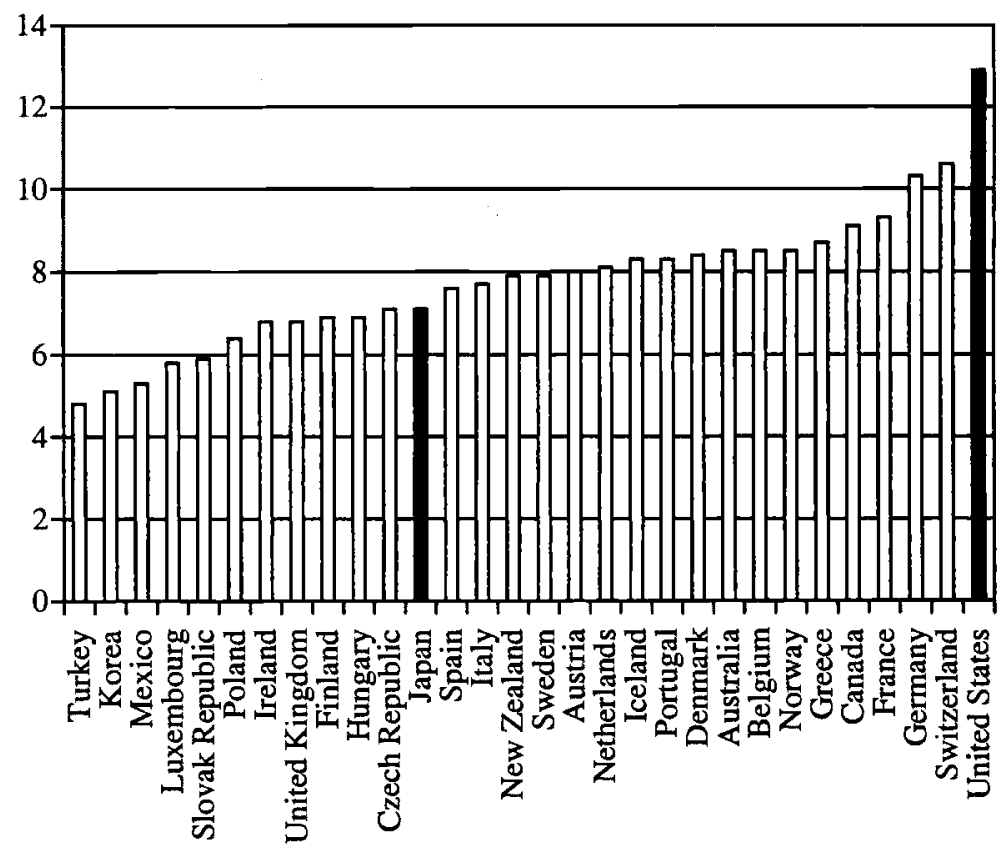

Fig. 2.2 Medical spending as a share of GDP Source: OECD (2002).

izontal axis of figure 2.4 is medical spending as a share of GDP. The vertical axis is life expectancy. A regression line indicates a positive relation between the two, although this is driven primarily by the very low income countries (Turkey, Hungary, and the Slovak Republic). Among higher income countries, there is no relation between spending and health outcomes.

As we indicated in the preceding, we do not interpret this result as suggesting that the marginal value of medical care is low. That may be the case, but it is not proven by this comparison. Rather, the comparison illustrates the need to explore the issue further. What role do medical systems play in influencing these outcomes? Do system features relate to performance? The remaining sections of the paper start down this path.

\subsection{Insurance Coverage in the United States}

There is no single health care system in the United States. Rather, health insurance in the United States is provided through a mixture of public and private programs. The principal public plans are Medicare, which provides insurance for the elderly and some disabled nonelderly, and Medicaid, which provides insurance for poor women and children under sixty-five 


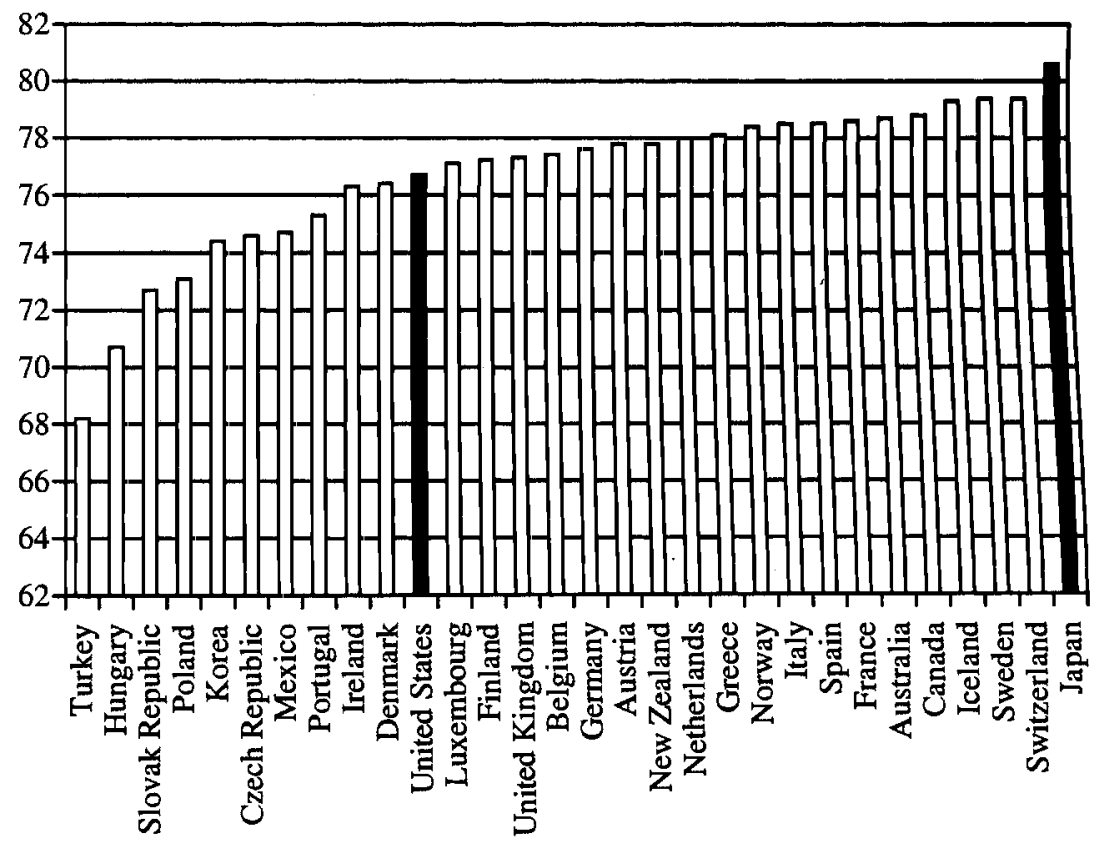

Fig. 2.3 Life expectancy at birth

Source: OECD (2002).

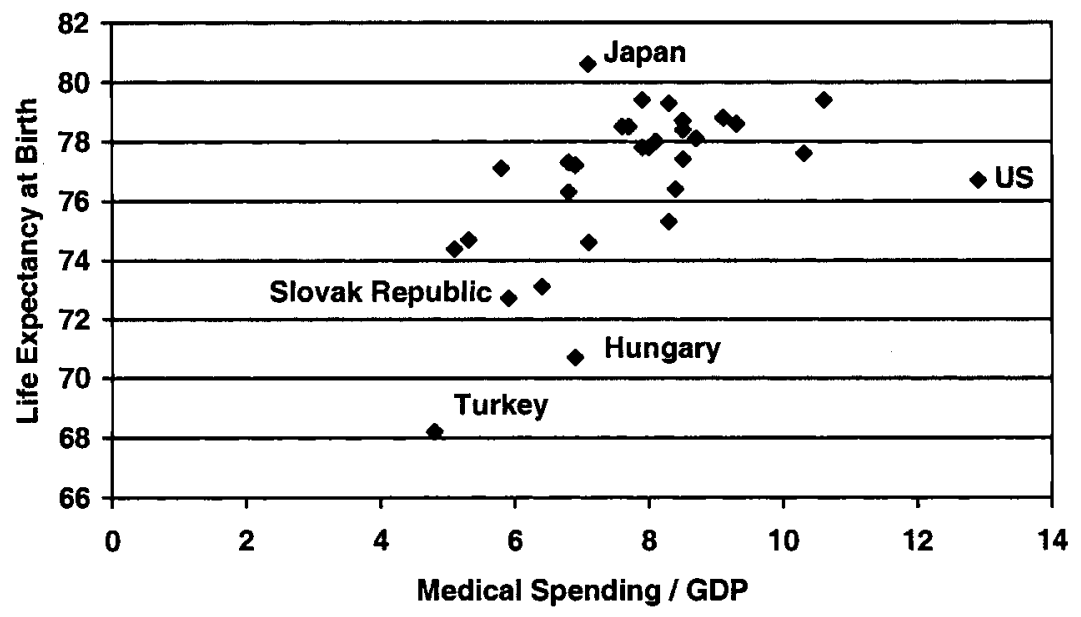

Fig. 2.4 Relation between medical spending and life expectancy Source: OECD (2002). 
(on a means-tested basis), the blind and disabled, and long-term care for persons age sixty-five and older. Employer-provided plans are the principle source of insurance for the nonelderly. We focus on the medical system for the elderly, but we begin by describing how insurance for the elderly fits into the total health care system.

Table 2.1 summarizes the sources of insurance coverage. We tabulate statistics separately for the nonelderly population (below age sixty-five) and the elderly. The source of care is presented in the left column of the table. Within each age group, we show the share of people with that source of insurance coverage and total spending for that age group accounted for by that source. Spending includes all medical services, with one exception: most long-term care spending is not accounted for in these data (most people in nursing homes are not in the spending sample). This reduces the share of spending for the elderly that is accounted for by Medicaid and outof-pocket payments, but we do not have an easy way of adding that back in. Public insurance covers 97 percent of the elderly population and about

Table 2.1

Sources of health insurance and medical spending in the United States

\begin{tabular}{|c|c|c|c|c|c|c|}
\hline \multirow[b]{2}{*}{ Source } & \multicolumn{3}{|c|}{ Under age 65} & \multicolumn{3}{|c|}{ Age 65 and over } \\
\hline & $\begin{array}{l}\text { Nature of } \\
\text { coverage }\end{array}$ & $\begin{array}{c}\% \text { of } \\
\text { population }\end{array}$ & $\begin{array}{c}1 \% \text { of } \\
\text { payments }\end{array}$ & $\begin{array}{l}\text { Nature of } \\
\text { coverage }\end{array}$ & $\begin{array}{c}\% \text { of } \\
\text { population }\end{array}$ & $\begin{array}{c}\% \text { of } \\
\text { payments }\end{array}$ \\
\hline Public insurance & & 16 & 17 & & 97 & 65 \\
\hline Medicare & Disabled & 2 & 4 & $\begin{array}{l}\text { Near } \\
\text { universal }\end{array}$ & 96 & 58 \\
\hline Medicaid & $\begin{array}{l}\text { Poor women } \\
\text { and children; } \\
\text { Blind and } \\
\text { disabled }\end{array}$ & 11 & 10 & $\begin{array}{l}\text { Acute care } \\
\text { for poor; } \\
\text { Long-term } \\
\text { care for poor }\end{array}$ & 10 & 4 \\
\hline Private insurance & & 72 & 54 & & 61 & 17 \\
\hline Employer & $\begin{array}{l}\text { Workers and } \\
\text { dependants }\end{array}$ & 66 & & $\begin{array}{l}\text { Employer } \\
\text { retiree } \\
\text { policies }\end{array}$ & 34 & \\
\hline Individual & $\begin{array}{l}\text { Family- } \\
\text { purchased } \\
\text { policies }\end{array}$ & 6 & & $\begin{array}{l}\text { Individually } \\
\text { purchased } \\
\text { supplemental } \\
\text { plans }\end{array}$ & 32 & \\
\hline Uninsured & & 16 & $21^{\mathrm{a}}$ & & 1 & $16^{\mathrm{a}}$ \\
\hline Other & & $6^{\mathrm{b}}$ & & & $2^{\mathrm{b}}$ & \\
\hline Share of total & & 87 & $\begin{array}{c}65 \\
(\$ 1,516)\end{array}$ & & 13 & $\begin{array}{c}35 \\
(\$ 5,662)\end{array}$ \\
\hline Total & & 100 & 100 & & 100 & 100 \\
\hline
\end{tabular}

Sources: Coverage data are from the Current Population Survey, March 2002. Spending data are from the Medical Expenditure Panel Study, 1997.

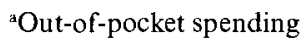

'Workers' compensation, other insurance (auto, etc.). 
16 percent of the nonelderly population. Medicare is the dominant public program for the elderly, while Medicaid is more important for the nonelderly. The majority of the nonelderly, nearly three-quarters, are covered by private insurance. Most of this is provided through employment, but a significant share comes from individual purchase as well. The quality of this coverage varies by employer.

Sixteen percent of the nonelderly population is without health insurance, compared to less than 1 percent for the elderly. In total, 46 million Americans are uninsured. The uninsured are a heterogenous group. Some are young and perhaps feel that health insurance is not a pressing need, others are poor and don't buy insurance, many are unemployed or employed by small firms that don't provide insurance, still others have chronic diseases that prevent them from buying insurance. Some of the uninsured are eligible for Medicaid ${ }^{3}$ but don't use the insurance. Many of the uninsured receive care through hospital emergency rooms. Much of this care is for serious illness or accidents, providing a sort of partial catastrophic insurance paid for by insured patients who pay more than the price of their care.

The share of medical spending paid for by various sources of insurance is shown in the next columns of table 2.1. In total, 35 percent of medical spending is for the elderly (the elderly make up about 13 percent of the population). At the time care is received, payment for the elderly comes from six sources-Medicare, Medicaid, privately purchased Medigap insurance, employer-provided retiree health insurance, out-of-pocket payments, and other miscellaneous sources. Medicare is the dominant payer, accounting for 58 percent of total spending. Including both Medicare and Medicaid payments, government programs pay for nearly two-thirds of the medical bills of the elderly. (The share would be somewhat lower if long-term care spending were included.) Private insurance and out-of-pocket payments account for the bulk of the remainder, in roughly equal proportions.

A large proportion of out-of-pocket payments are for outpatient prescription drugs. In addition, much long-term care spending is out of pocket, although these expenses are undercounted in this table.

In the nonelderly population, about 50 percent of medical payments are made by private insurers. Government payments account for 17 percent of spending, and out-of-pocket spending by individuals accounts for another 21 percent.

\subsubsection{Who Pays for Insurance?}

Inpatient insurance (Part A) under Medicare is paid for by the young through a 2.9 percent payroll tax-half of which is paid for by the employer and half by the employee. Outpatient care (Part B) under Medicare

3. About 40 percent of children who are uninsured are eligible for Medicaid, and additional children are eligible for coverage under the Children's Health Insurance Program (CHIP). 
is financed through Supplementary Medical Insurance. Enrollee premiums are 25 percent of the cost of the insurance. The remainder comes out of general government revenues. In addition, Medicare beneficiaries can buy Medigap private insurance to cover the difference between Medicare payments and charges for care. About two-thirds of Medicare beneficiaries are covered by a private insurance policy in addition to Medicare--half are employer-provided retiree plans and half are purchased individually. As we discuss in the following, together these plans provide first-dollar coverage for a large portion of care, encouraging excessive use of services (Newhouse 1993).

Insurance premiums under employer-provided plans for the nonelderly are typically shared between the employer and the employee. On average, about 75 to 80 percent of premiums are paid for by the employer and the remainder by the employee. Unlike wages and salaries, compensation to employees in the form of health insurance is not taxed. Thus employees have a strong incentive to take compensation in the form of health insurance (Feldstein 1973). And employees have a strong incentive to encourage generous insurance plans with low out-of-pocket copayments, which are typically taxed. Thus, for the under sixty-five group as well, part of the system pushes toward first-dollar coverage with little constraint on expenditure at the time care is received.

The out-of-pocket bill facing individuals is the direct spending on medical care services plus the family cost of health insurance. These totals are not readily apparent in table 2.1 , which records the payer at the time the service is used. To flow through these insurance payments to individuals, table 2.2 shows family spending on medical care. Among the elderly population, insurance payments are about $\$ 1,800$ per family (largely for supplemental Medigap insurance coverage and the employee part of employer-sponsored retirement coverage), and direct costs are about the same magnitude. The amounts are similar in the nonelderly population, about $\$ 1,900$ for direct payments and health insurance.

In addition to these payments, the nonelderly also pay indirectly for the

Table 2.2

Family payments for medical care (\$)

\begin{tabular}{lcc}
\hline Source & Under 65 & Over 65 \\
\hline Direct & 1,857 & 3,493 \\
Insurance payments & 884 & 1,775 \\
Out-of-pocket & 973 & 1,719 \\
Employer & 2,651 & \\
Total & 4,508 & \\
\hline
\end{tabular}

Sources: Direct spending is from the Consumer Expenditure Survey, 2001. Employer payments are estimated assuming that three-quarters of insurance premiums are paid by employers. 
employer's portion of employer-provided health insurance. Though the employer writes the check for insurance, economic research establishes quite clearly that the ultimate incidence of these payments is on workers (Summers 1989; Gruber 1994). A rough guess of these amounts is about $\$ 2,700$ per family. Spending on health insurance and medical care is thus perhaps $\$ 4,500$ in total for the nonelderly population.

The final set of payments are taxes to pay for public programs and the implicit income that retirees give up earlier in life to pay for employerprovided medical care when retired. The incidence of these payments by age is somewhat harder to assess. Previous taxes paid by the elderly for Medicare do not cover their current use, for example, and so some of that cost is paid for by the current young. The same is likely true with employerprovided supplemental insurance. Rather than deal with these generational incidence questions, however, we limit ourselves to payments targeted to immediate services use.

\subsubsection{Gradations in Insurance Coverage}

To this point, we have treated all private health insurance as identical. In practice, there are enormous differences in the types of insurance that people have. The services covered by Medicare differ from those covered by Medicaid and private insurance. Table 2.3 shows this comparison. Private insurance policies generally cover hospital care, physician services, outpatient tests, and prescription drugs. Long-term care is usually not covered, but those services are used infrequently by the nonelderly population.

Medicare is significantly less generous than the typical private insurance policy. Medicare covers hospital services, physician expenses, and laboratory tests. It does not cover outpatient prescription medications, however, and only very limited coverage for long-term care. Partly as a result of this, almost all elderly supplement Medicare in one form or another. As explained previously, some beneficiaries purchase private Medigap policies to cover cost sharing and occasionally prescription drugs. Other beneficiaries obtain supplemental insurance from a former employer. Still others enroll in Medicare Health Maintenance Organizations (HMOs) to obtain additional services, a topic we return to in the following. Finally, the poor

Table 2.3

Typical coverage in insurance policies

\begin{tabular}{lccc}
\hline & Private & Medicare & Medicaid \\
\hline Hospital & $\checkmark$ & $\checkmark$ & $\checkmark$ \\
Physician & $\checkmark$ & $\checkmark$ & $\checkmark$ \\
Laboratory & $\checkmark$ & $\checkmark$ & $\checkmark$ \\
Prescription medications & $\checkmark$ & Modest & $\checkmark$ \\
Long-term care & & & \\
\hline
\end{tabular}




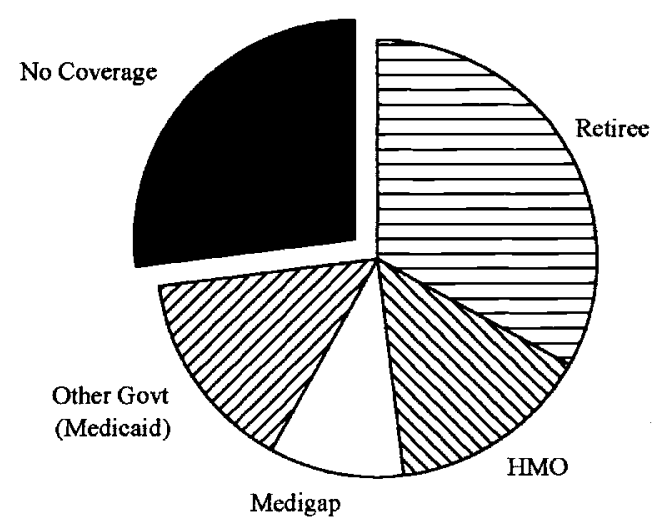

Fig. 2.5 Prescription drug coverage among the elderly

Note: Data are for 1998.

elderly have prescription drug and long-term care services paid for by Medicaid.

Figure 2.5 shows the share of elderly with insurance coverage for prescription drugs and the source of that coverage. Three-quarters of the elderly have prescription drug coverage. The bulk of such coverage is obtained through prior employment, with HMOs, private Medigap policies, and other public programs supplying the remainder.

Medicaid covers the range of acute and long-term care services. On paper, Medicaid is among the most generous insurance plans available. In practice, though, Medicaid payments are so tightly constrained that access to care for Medicaid beneficiaries is a significant concern. We do not focus greatly on the Medicaid program in the remainder of the paper.

The Medicaid experience raises the broader point that access is not just about covered services. The nature of the insurance policy differs in other ways as well. A major issue in the United States is whether the receipt of medical care is managed. Managed care is a form of vertical integration in medicine. Rather than dividing insurance from medical care provision, managed care integrates the two, having insurers become involved in what care is provided and how it is delivered. Private insurance has a range of different types of management. We provide more details in the following, but note here that the system is more complex than table 2.3 suggests.

There is some managed care in Medicare, but it is decidedly less important. About 90 percent of Medicare beneficiaries are in the traditional program, where the government determines the payment rates and access rules. The remaining 10 percent are in managed care plans, usually an HMO. Because of the dominance of the traditional Medicare program, we refer to Medicare as if it were just that policy. 


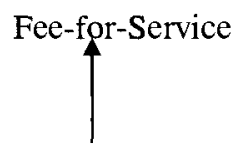

Traditional Medicare, Private Insurance

Medicare Physicians Salary

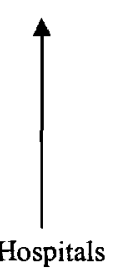

Capitation

Managed Care Physicians

Fig. 2.6 Characterization of reimbursement systems

\subsection{Reimbursing Providers}

Given the many different ways that Americans obtain health insurance, it is not surprising that there is a wide range of reimbursement systems in use. Further, the reimbursement systems differ enormously in the incentives they provide. ${ }^{4}$

Perhaps the most critical feature of reimbursement systems is the degree to which payments are related to costs. Some reimbursement systems pay more when more care is provided, and others pay less. Consider a linear relation between payment for a service provided and the various costs of that service:

$$
\text { Payment }=a+b \cdot \text { Practice Cost }+c \cdot \text { Time Cost, }
$$

where $a, b$, and $c$ are parameters of the payment system. Practice costs include office expenses, nonphysician administrative personnel, malpractice insurance, and supplies. The time costs represent the opportunity costs of the physician devoting additional hours to care.

Historically, medical care in the United States was paid for on a fee-forservice basis. In this system, total reimbursement is equal to the cost of care provided (with some division between insurer and enrollee payments. In terms of equation (1), $a=0, b=1$, and $c=1$. Fee-for-service insurance is shown at one end of the scale of payment generosity in figure 2.6.

There is a distinction between marginal and average cost that is important in understanding the incentives of fee-for-service systems. Medical care has very high fixed costs, but the marginal cost of additional production is often low. For example, it costs about $\$ 800$ million to develop a new drug (DiMasi 2003), but the cost of producing additional pills once the

4. For a review of physician payment systems and the incentive they create, see McGuire (2000). 
drug is developed is only pennies. Similarly, many of the costs for a physician are sunk costs - the opportunity cost of medical education most particularly. Other costs are fixed costs, depending only on the decision to practice medicine. Examples of these costs include malpractice insurance, office rent, and equipment overhead. True marginal cost is low.

Traditional fee-for-service payment systems paid on the basis of average costs. This reimburses physicians for sunk and fixed costs as well as marginal costs. In practice, this creates large profits for providing additional care because payment far exceeds costs at the margin. Thus, fee-for-service payment systems strongly encourage provision of medical care in almost all circumstances.

A somewhat less generous set of incentives is provided by a salary system. In many HMOs in the United States and in some European countries, physicians are paid a salary for providing care. The salary system corresponds to a payment rule where $a>0, b=1$, and $c=0$. The physician earns a fixed amount of money and does not have to pay for any practice expenses but is not reimbursed more for additional time costs.

The salary system provides fewer incentives for care provision than does the fee-for-service system. In a salary system, additional care provided is not reimbursed at the margin, so there is no financial incentive to do more. In particular, because the doctor's time cost is not reimbursed at the margin, the doctor has an incentive to cut back on time inputs. A doctor on a salary earns the same amount if he shows up for a full day or half day of work (assuming his salary is not docked). Thus, doctors will attempt to arrive late and leave early and to substitute tests and devices for additional time.

The ability of physicians to do this varies by setting. In some countries, such as Italy, monitoring of physicians is poor, and doctors routinely violate the guidelines as to hours that must be worked (Cutler 2002a). In many HMOs, in contrast, monitoring is stronger, and physicians are not able to shirk.

The third type of payment system is capitation. In the extreme version of this system, physicians are paid a fixed amount and must pay for all care provided out of the capitation amount. In terms of equation (1), $a>0, b=$ 0 , and $c=0$. This type of system is most common with primary care physicians. If a patient of a doctor paid this way uses medications that the doctor prescribes or is admitted to the hospital, the costs of the medications or hospitalization are paid for out of the capitation amount.

There are a complex array of capitation systems used in practice. Some physicians are capitated for care used in the primary setting, medications, and nonemergency hospitalizations, but not for emergency hospitalizations. Others are capitated for all costs, but have reinsurance for very expensive patients. Still others have varying degrees of capitation depending on total spending in the practice as a whole. 
Regardless of the specifics, capitated systems have the feature that physician earnings are negatively related to the amount of care provided. Doctors that do more earn less. Not surprisingly, the incentives of this system are the weakest (as shown in figure 2.6). A purely profit maximizing doctor paid a capitation rate would not see patients at all and would not provide any care. Of course, HMOs monitor physician behavior, and patients will find other doctors if no care is provided, meaning that future income will decline. Thus, the example is grossly exaggerated. But it shows the nature of the incentives.

In addition to varying across payers, reimbursement systems in the United States have changed over time. Figure 2.6 illustrates the evolution of these systems. Historically, both Medicare and private insurers reimbursed services on a fee-for-service basis. The reason for this was practical. When private insurers started to cover medical care, they did not know how to pay for care; medical care was separate from insurance. Doctors had list prices, however, and so insurers paid those prices. This ultimately turned into the fee-for-service system.

Over time, both Medicare and the private sector have moved away from fee-for-service payment. Medicare currently pays physicians on a fee schedule, based loosely on the estimated cost of services provided. In a number of detailed studies, the government attempted to determine the cost of different services and now reimburses physicians on that basis. The payment is still per service performed, but is somewhat less generous than it once was.

Bigger changes have occurred in the payment system for hospitals. Since the early 1980 s, payment for Medicare patients admitted to hospitals has been under a partially capitated system termed the prospective payment system (PPS). When a Medicare patient is admitted to a hospital, the hospital reports the diagnosis the patient received and whether a surgical procedure was performed. These two attributes are used to classify patients into one of about 470 diagnosis related groups (DRGs). The payment received for the patient depends only on the DRG and hospital factors, such as the region of the country and whether the hospital is a teaching hospital, not the specific services provided (other than how the surgical or nonsurgical distinction affects DRG coding).

An example illustrates how this system works. Consider the treatment of patients with acute myocardial infarction, or heart attack (see Cutler and McClellan 1998). A patient with a heart attack will almost always be admitted to a hospital. Upon admission, the hospital will administer a number of medications, including aspirin, beta-blockers, and, potentially, thrombolytics. Under the old fee-for-service payment system, each of these medications would be reimbursed separately. In the DRG system, there is no additional payment for providing them.

Many patients with a heart attack receive cardiac catheterization, a di- 
agnostic procedure that measures the extent of blood flow to the heart. Catheterization is a surgical procedure; hence patients receiving a catheterization will be in a different DRG than patients who do not receive catheterization. The exact cost of the catheterization is not a factor in payment; however, a hospital that takes longer for each catheterization will receive no more money than a hospital that takes less time.

Depending on the results of the catheterization, additional procedures may be performed. Bypass surgery is a procedure to reroute blood flow around the blocked area in the coronary arteries. Angioplasty is used to clear the original blockage and restore blood flow in the arteries. Each of these procedures moves the patient into a more highly reimbursed DRG. But the specifics of the services provided - the type of catheter, the number of recovery days in the hospital, and the follow-up tests-are not reimbursed separately.

In the DRG system, therefore, heart attack patients will be classified into one of four DRG groups: those medically managed only (without any surgical procedures), those who receive cardiac catheterization but not bypass surgery or angioplasty, those who receive bypass surgery, and those who receive angioplasty. ${ }^{5}$ The incentives of this system are therefore relatively strong to perform surgery but weak to perform additional nonsurgical care in hospitals.

In the private sector, reimbursement is more variable. Some physicians are paid on a fee-for-service basis, although usually one where the payments are substantially less generous than they were formally. More common is for physicians to be paid on a salary basis or by full or partial capitation. Hospital payments are generally along the lines of Medicare, with a payment per admission (using the DRG system) or per day of care received (a per diem system). In the latter methodology, the payment does not vary with the services provided in each day. Thus, intensive care in the stay is discouraged, while marginal days of care are not so heavily penalized. For both hospitals and physicians, the rate of payment is generally lower in the private sector than in Medicare. As a result, the incentives for limited service provision are even stronger.

\subsubsection{Evidence on Reimbursement Incentives}

How much do these incentives matter? A large literature has examined the response of services provided to physician payment incentives (see Cutler and Zeckhauser [2000] for a summary). The issue is complicated because the incentives of patients may be different from those of physicians: doctors may have incentives to provide less care, but patients may want

5. There is a little variation in these groups between patients with complications and those who do not have complications, but this is based on diagnoses of the patient, not treatments provided. 
more. The equilibrium in such a situation is unclear. Still, the literature shows unambiguously that reimbursement incentives do affect the amount of medical care provided.

The strongest evidence for this effect comes from work of Mark McClellan (1997), based on the experience of the Medicare program. McClellan looked at how surgical and nonsurgical hospital admissions changed after the PPS was implemented. Recall that surgery increases the DRG payment the hospital receives; thus, surgical admissions should rise after PPS. Nonsurgical admissions were predicted to fall, however, because the elimination of fee-for-service reimbursement made those admissions less generous.

Figure 2.7 shows admission rates for surgical and nonsurgical admissions before and after the implementation of PPS. The results strikingly confirm the theory. Admissions for nonsurgical patients fell substantially with the implementation of PPS; the decline was about 40 percent. Surgical admissions rose by nearly the same percent. The timing of this change is perfectly coincident with PPS.

Evidence from managed care in the private sector shows major reductions in hospitalization rates and lengths of hospital stay in response to those incentives (Glied 2000). Admission rates in managed care plans are well below rates in fee-for-service plans, and lengths of hospital stay are shorter as well. The total saving in hospital care is about 20 percent. Some of this difference is certainly due to reimbursement incentives, although direct regulations on use of care (described in the next section) are important, too.

Overall, the United States' medical care system has become substan-

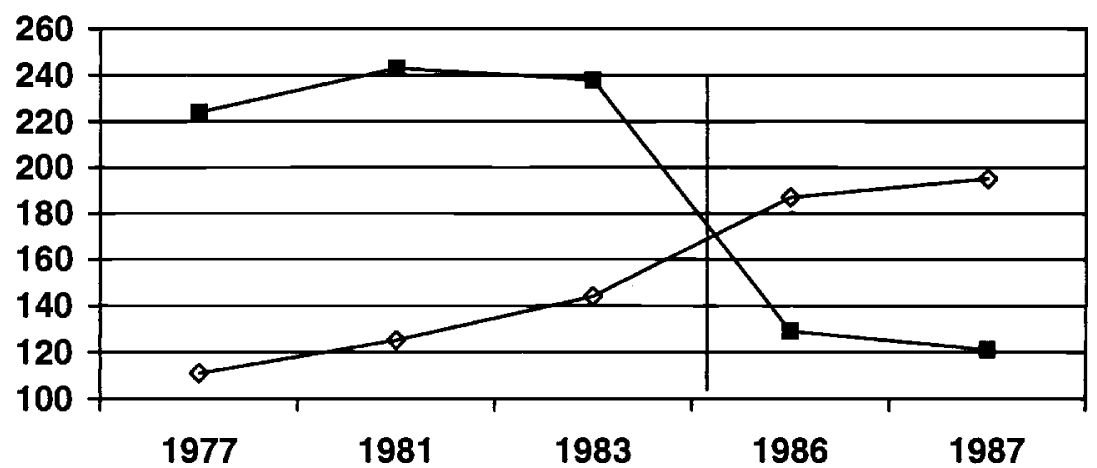

$\diamond$ Procedure-Based DRGs - Diagnosis-Based DRGs

Fig. 2.7 Change in admissions after prospective payment

Source: McClellan (1997). 
tially less generous in payment for care in the past two decades, and this has affected the care provided.

\subsection{Access Rules}

Access rules are among the most complex areas of medical care. There are myriad varieties of medical services that can be provided, with different rules for each. For example, patients may have different access to primary care, mental health specialists, and orthopedists. We synthesize the access rules in three parts. The set of services covered by insurance is the first element. Are prescription medications covered by the policy? We discussed variations in coverage previously. We focus here on two other parts of access: financial payments that individuals have to make when they use care (termed cost sharing) and nonfinancial barriers to the use of services.

\subsubsection{Cost Sharing in Insurance}

All insurance policies require patients to pay something when they access care. Cost sharing evolved as a way to limit moral hazard - excessive use of medical services only because they are insured. Since its beginnings, cost sharing has become much more elaborate.

Traditionally, private insurance policies had a varying schedule of patient payments. A typical private schedule is shown in figure 2.8. The deductible is the amount that a patient paid before insurance covered any care. A typical insurance policy had a deductible of about $\$ 500$. After the deductible, costs were split between the insurer and the enrollee. The share of enrollee payments is termed the coinsurance rate; a standard coinsurance rate was 20 percent. Coinsurance would continue until the patient

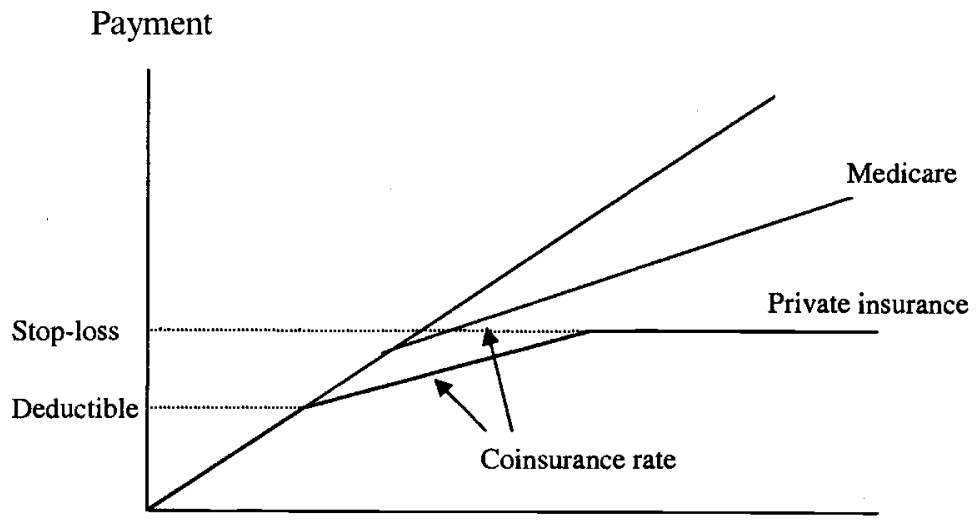

Cost

Fig. 2.8 Cost sharing in traditional insurance 
reached a specified maximum, termed the stop-loss. Past this point, the insurer would pay all the costs of medical care. A common stop-loss was about $\$ 1,500$.

The optimal insurance policy balances risk sharing against moral hazard. Making individuals pay more for medical care reduces the amount of moral hazard. But it also increases the financial risk that people are exposed to. In the optimal policy, these gains and losses are equal at the margin-a small increase in coinsurance rates leads to as much loss from increased risk as it brings in benefits from reduced moral hazard.

In practice, the tax system subsidized generous insurance and thus tilted policies toward being overly generous (Feldstein 1973). Employer payments for health insurance are not counted as income for tax purposes, while individual payments are. It was noted in the preceding that this provides incentives for people to have employer-based policies rather than individual policies. In addition, it encourages running as much money as possible through insurance rather than leaving costs to be paid for out-ofpocket, as insured services are paid for with pretax dollars rather than posttax dollars. This leads to a welfare loss-too little moral hazard and not enough risk sharing.

A substantial literature has examined the impact of this tax subsidy on overall medical spending and the losses to the economy. Martin Feldstein pioneered these calculations in the $1970 \mathrm{~s}$, and since then others have pursued this line of analysis (see, e.g., Enthoven 1993). Determining a final value for the impact of the tax subsidy on spending is complex, as the chain of causal events is long. The tax subsidy influences the structure of insurance policies, which in turn affects how much care people use and, thus, medical spending. A consensus estimate is that total medical spending is perhaps 5 to 10 percent higher as a result of the tax subsidy (Cutler 2002b).

The traditional Medicare program has the opposite problem. Cost sharing in the Medicare system is very high, particularly for catastrophic expenses. It was already noted that Medicare does not cover outpatient prescription medications, leading beneficiaries to face substantial risk. In addition, cost sharing for the set of covered services is high.

Table 2.4 shows the cost-sharing provisions in Medicare in detail, and figure 2.8 shows the schedule of payments for a typical enrollee. ${ }^{6}$ Beneficiaries who use outpatient services have a deductible of $\$ 100$ and a 20 percent coinsurance rate above that. The $\$ 100$ deductible is not particularly large, but the coinsurance occurs without limit. This exposes Medicare beneficiaries to substantial risk--far more than in the private sector. Hospital cost sharing is also perverse. Medicare beneficiaries face a deductible equal to one day of hospital care, about $\$ 800$ currently. This is very high by

6. We assume the person has one hospitalization during the year and no laboratory tests or mental health care utilization. 
Table 2.4

Cost sharing in Medicare, 2002

\begin{tabular}{|c|c|}
\hline Service & Beneficiary cost \\
\hline \multicolumn{2}{|l|}{ Part A } \\
\hline \multirow[t]{5}{*}{ Inpatient hospital } & First stay in benefit period \\
\hline & $\$ 840$ deductible for first stay \\
\hline & $\$ 210$ per day cost sharing for days $61-90$ \\
\hline & Reserve days (60 lifetime) \\
\hline & $\$ 420$ per day cost sharing for lifetime reserve days \\
\hline \multirow{3}{*}{ Skilled nursing facility } & No cost sharing for first 20 days \\
\hline & $\$ 105$ per day cost sharing for days $21-100$ \\
\hline & No coverage after 100 days \\
\hline Hospice care & Nominal payment for drugs and respite care \\
\hline \multicolumn{2}{|l|}{ Part B } \\
\hline Overall deductible & $\$ 100$ per year \\
\hline Physician services & 20 percent coinsurance rate \\
\hline Outpatient hospital care & 20 percent coinsurance rate based on median charge index \\
\hline Ambulatory surgical & 20 percent of Medicare-approved amount \\
\hline Laboratory services & None \\
\hline Outpatient mental health & 50 percent coinsurance of Medicare-approved amount \\
\hline Preventive services & $\begin{array}{l}20 \text { percent coinsurance of approved amounts, waived for } \\
\text { some services }\end{array}$ \\
\hline \multicolumn{2}{|l|}{ Parts A and B } \\
\hline Home health & None \\
\hline
\end{tabular}

Source: Hackbarth (2003).

private standards. After the deductible is paid, Medicare pays for the entire amount for the next sixty days of care. Beyond the sixty-day window, beneficiaries face increasing amounts of cost sharing for the next thirty days and then no further government reimbursement, ${ }^{7}$ again exposing beneficiaries to large financial risk. By any calculation, the traditional Medicare program leaves people with far more financial risk than is optimal.

In response to this high degree of risk bearing, it is natural for Medicare beneficiaries to want more coverage than Medicare provides. For the lowincome population, Medicaid provides this additional insurance, paying for the cost sharing required by the perverse Medicare reimbursement schedule.

The higher income population does not qualify for Medicaid but receives supplemental coverage in other ways. Some employers provide retiree health benefits that pay for the cost sharing required by Medicare. Others purchase individual insurance policies that supplement Medicare, termed Medigap insurance. Still others enroll in HMOs, which have lower cost sharing. All told, about three-quarters of the elderly have some supplemental insurance, through Medicaid or private supplements.

7. People do have sixty lifetime reserve days that they can use. Cost sharing in those days is half of the average daily cost. 
Both employer and individual supplements provide first-dollar coverage-there is generally no cost sharing for hospital or physician services. The reason why first-dollar coverage is the norm is subtle. First-dollar coverage clearly leads to moral hazard. But a lot of the additional utilization is paid for by the traditional Medicare program, not the supplemental insurance. A beneficiary that goes to the doctor more as a result of having supplemental insurance pays for only 20 percent of the additional use in the insurance premium; the remaining 80 percent is covered by Medicare.

As a result, the cost of Medicare is much higher than it would be without supplemental insurance. Estimates suggest that people who have supplemental insurance cost Medicare about 20 percent more than they would without supplemental coverage (Christensen and Shinogle 1997). Of course, a better number to know is the additional spending beyond what Medicare would optimally spend if it were configured with the most appropriate degree of cost sharing. Because the optimal policy is more generous than the current policy, the savings from the optimal policy are lower. There are no estimates of these savings, however.

\subsubsection{Nonfinancial Restrictions}

All insurance plans impose some nonfinancial barriers to access medical care. People need physician approval before they can receive prescription medications or be admitted to a hospital, for example. But some plans have additional barriers to the use of care.

In the Medicare program, there are essentially no barriers to the use of care. Patients can see whatever doctor they want at whatever time they want. Referrals are not required, and no providers are out of bounds. ${ }^{8}$ This led to an era of substantial increase in services provided. Recently, reimbursement has moved away from a pure fee-for-service basis into a more capitated basis, providing some incentives for doctors to do less. But the patient side is still very generous.

There are substantially more barriers to receipt of care in private insurance. The most important barriers are in managed care plans. Managed care was noted in passing earlier, but is particularly relevant at this point. We provide a taxonomy of managed care in table 2.5 .

The most limited managed care arrangement is a managed indemnity insurance policy. It bundles a traditional indemnity policy with some utilization review-monitoring of providers to restrict the services that are performed and deny or reduce payment. For example, many insurance plans require that nonemergency hospital admissions be precertified. Utilization

8. This presents an interesting contrast with the extent of cost sharing, which was noted previously to be very high. If the traditional system were all that people had, there would be conflicts between people who want to spend less and doctors with incentives to do more. Because so many people have supplemental insurance, however, there is little restraint on care from the patient side. 
Key characteristics of insurance policies

\begin{tabular}{|c|c|c|c|c|}
\hline \multirow[b]{2}{*}{ Dimension } & \multirow[b]{2}{*}{$\begin{array}{l}\text { Indemnity } \\
\text { insurance }\end{array}$} & \multicolumn{3}{|c|}{ Managed care } \\
\hline & & $\mathrm{PPO}$ & $\begin{array}{c}\text { IPA/Network } \\
\text { HMO }\end{array}$ & $\begin{array}{c}\text { Group/Staff } \\
\text { HMO }\end{array}$ \\
\hline Qualified providers & Almost all & $\begin{array}{l}\text { Almost all } \\
\text { (network) }\end{array}$ & Network & Network \\
\hline Choice of providers & Patient & Patient & $\begin{array}{l}\text { Gatekeeper } \\
\text { (in network) }\end{array}$ & $\begin{array}{l}\text { Gatekeeper } \\
\text { (in network) }\end{array}$ \\
\hline Payment of providers & Fee-for-service & Discounted FFS & Capitation & Salary \\
\hline Cost sharing & Moderate & $\begin{array}{l}\text { Low in network; } \\
\text { High out of network }\end{array}$ & $\begin{array}{l}\text { Low in network; } \\
\text { High out of network }\end{array}$ & $\begin{array}{l}\text { Low in networ } \\
\text { High/all out of } \\
\text { network }\end{array}$ \\
\hline Roles of insurer & Pay bills & $\begin{array}{l}\text { Pay bills; } \\
\text { Form network }\end{array}$ & $\begin{array}{l}\text { Pay bills; } \\
\text { Form network; } \\
\text { Monitor } \\
\text { utilization }\end{array}$ & Provide care \\
\hline Limits on utilization & Demand-side & Supply side (price) & $\begin{array}{l}\text { Supply side } \\
\text { (price, quantity) }\end{array}$ & $\begin{array}{l}\text { Supple side } \\
\text { (price, quantit }\end{array}$ \\
\hline
\end{tabular}

Source: Cutler and Zeckhauser (2000).

review can be conducted on an individual basis, as in tissue review committees or on a statistical basis, by monitoring a physician or hospital's overall utilization. As figure 2.9 shows, managed indemnity insurance, though nonexistent in 1980, claimed a 41 percent share of private insurance coverage by 1992 . The share has fallen to 22 percent today.

Preferred provider organizations (PPOs), a second type of managed care, form a network of providers, including physicians, hospitals, pharmaceutical companies, and others, and control costs by securing discounts from them. The quid pro quo for the discounted fee is that insured participants are steered to in-network providers. Out-of-network providers may get reduced coverage on a limited basis (with higher cost sharing, for example) or may not be covered at all. In 1991, the typical PPO had an in-network coinsurance rate of 10 percent and an out-of-network coinsurance rate of 20 percent. PPOs usually impose preauthorization requirements as well, though they are rarely especially strict. As figure 2.9 shows, PPO enrollment, zero in 1980, now makes up about one-quarter of the privately insured population.

Full integration creates the strongest link between insurance and provision. In the United States, these merged entities are called HMOs. There are two major types of HMOs. Within a group or staff HMO - the most common form, with Kaiser being the best-known example - physicians are paid a salary and work exclusively for the HMO. The HMO may have 


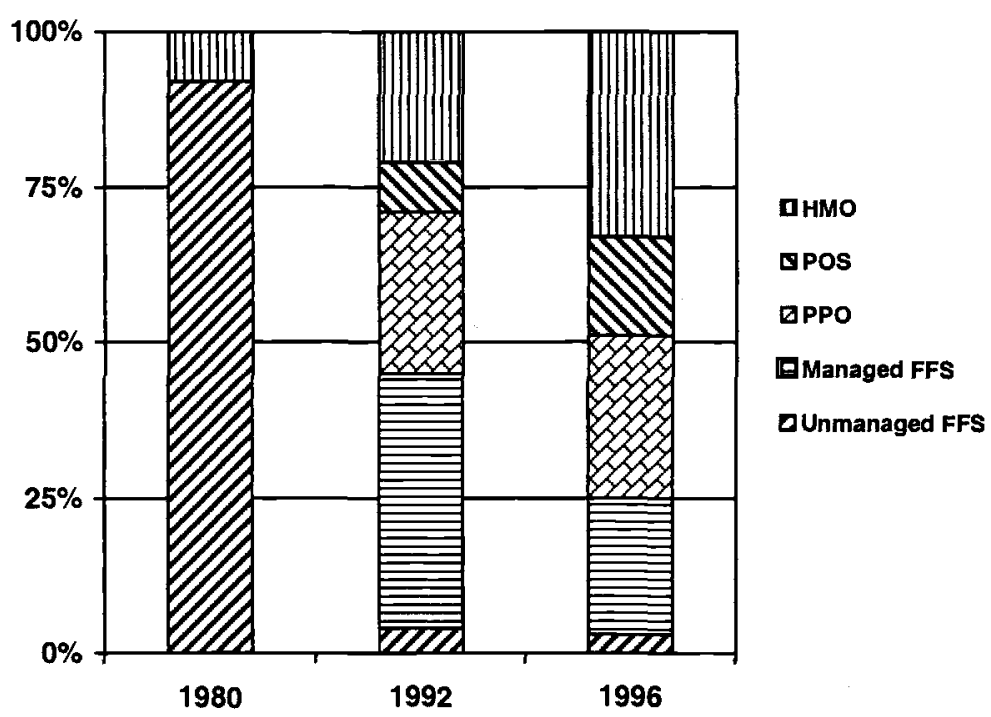

Fig. 2.9 Changes in private health plan enrollment

hospitals on contract or may operate its own hospital. Independent practice associations (IPAs), or network model HMOs, represent a more recent innovation in managed care. ${ }^{9}$ These plans neither employ their own physicians nor run their own hospitals. Instead, they contract with providers in the community.

Health maintenance organizations employ a range of mechanisms to limit utilization. They reflect the traditional economic instruments of regulation, incentives, and selection of types. Health maintenance organizations frequently regulate physicians' practices, for example, limiting the referrals they can make or the tests they can order. In addition, there are financial incentives for physicians in HMOs to do less, as noted earlier. Moreover, HMOs monitor the services that physicians provide. They may reward parsimonious resource use directly with compensation, though more likely with perks or subsequent promotion. Extravagant users are kicked out of the network. Finally, because physicians differ substantially in their treatment philosophies, HMOs can select physicians whose natural inclination is toward conservative treatment.

In some HMOs, patients can go outside of the network and still receive some reimbursement. This is termed a point of service (POS) option. But reimbursement out-of-network is not as generous as reimbursement within. Use of nonnetwork services, for example, frequently requires a deductible followed by a 10 to 40 percent coinsurance payment. 
The sweeping nature of insurer-provider interactions is indicated by figure 2.9 (see also Glied 2000). In 1980, over 90 percent of the privately insured population in the United States was covered by unmanaged indemnity insurance. By 1996, that share had shrunk to a mere 3 percent. Health maintenance organization enrollment of all forms (including POS enrollment) has increased from 8 percent of the population in 1980 (then predominantly group- or staff-model enrollment) to nearly half of the privately insured population today.

In exchange for tight access restrictions, most HMOs have very low patient cost sharing. A person might face a $\$ 10$ copayment for seeing a network physician, compared to full price for the first dollar of care in some indemnity insurance plans.

\subsubsection{The Impact of Nonfinancial Restrictions}

Managed care clearly reduces utilization of some types of care. Managed care plans have a higher ratio of primary care physicians to specialists than do nonmanaged care plans (Glied 2000). In addition, nonnetwork providers are much less likely to be seen than are network providers. Perhaps most significantly, however, these requirements allow for substantially lower prices paid for medical care. Exact data on prices in different insurance arrangements is not known, but it is not uncommon to find discounts of 30 percent on physician and hospital care for insurance plans with tight networks. These price reductions are a major reason why managed care plans cost less than traditional indemnity insurance plans (Altman, Cutler, and Zeckhauser 2003).

Further, the evidence does not suggest large adverse effects of managed care on health outcomes. Some studies find that patients are worse off, some find that they are better off, and most find that they are about the same. Summary reviews of the literature suggest no outcome differences between managed care and traditional insurance policies (Miller and Luft 1997).

Even with this profile---cost savings and no adverse impact on healthmanaged care is not very popular. Utilization review is the aspect of medicine that physicians dislike the most. Doctors feel their professional integrity is challenged by these restrictions and have protested vehemently. Patients do not like managed care either, in large part because of the perception that managed care restricts the care they can receive. The widespread interest in a Patient's Bill of Rights is testament to this concern. As a result of physician and patient opposition, the extent of utilization review has changed over time. Where utilization review was common in the early 1990s, it is rarer now. Instead, managed care plans have substituted more financial incentives (such as capitation) to encourage physicians to provide less care. 


\subsubsection{Comparisons with Other Countries}

The specific form of utilization review as we have described is most prevalent in the United States. But restrictions on utilization are widespread throughout the developed world. In most countries, utilization is restricted through overall limits on the availability of medical services. Canada, for example, imposes very tight controls on the number of hospitals that can acquire expensive new technologies. There is less technology than physicians would use by choice, so some rationing must occur. In practice, the rationing is done by physicians, who decide which patients most need access to the technologies.

The distinction between physician-driven rationing and insurer-driven rationing is fundamental in some ways but less important in others. Physicians are certainly happier with physician-driven rationing than with insurer-driven rationing, as they make the decisions in one case but have decisions imposed on them in the other. From the social perspective, however, both methods ration access to medical care. The empirical issue is whether that rationing works well and how much rationing is appropriate. International comparisons of medical care provided under different insurance arrangements should help to answer this question.

\subsection{Conclusion}

Because medical care systems are complex, they cannot be easily characterized. Still, some dimensions of organization are apparent. In this paper, we highlight three important domains of medical care: the rules about coverage, reimbursement between insurers and providers, and access to care.

While there is variability within the United States, we suggest the following simple summary. Coverage in the United States is spotty-quite good for the elderly, especially those with supplemental insurance, but not guaranteed for the nonelderly. Historically, reimbursement of providers was very generous, and access was open as well. Increasingly, though, the reimbursement and access routes are being restricted as insurers respond to moral hazard and the demand for cost containment.

The direction the medical system will go in the United States is not clear. Even in the past few years, reimbursement and access rules have changed, and coverage issues have dominated the public agenda. Changes along all three dimensions bear watching.

It is also important to extend this analysis to other countries. One of the central issues in all of health economics is determining which medical system is best. Only by characterizing existing systems and comparing outcomes across countries can we make progress in this effort. 


\section{References}

Altman, Daniel, David Cutler, and Richard Zeckhauser. 2003. Patient mix, treatment intensity, and cost in competing health plans. Journal of Health Economics 22 (1): $23-45$.

Baumol, William J. 1967. Macroeconomics of unbalanced growth: The anatomy of urban crises. American Economic Review 57 (3): 415-26.

Chernichovsky, Dov. 1995. Health system reforms in industrialized democracies: An emerging paradigm. The Milbank Quarterly 73 (3): 339-72.

Christensen, Sandra, and Judy Shinogle. 1997. Effects of supplemental coverage on use of services by Medicare enrollees. Health Care Financing Review 19 (1): 5-17.

Cutler, David. 2002a. Equality, efficiency, and market fundamentals: The dynamics of international medical care reform. Journal of Economic Literature 40 (3): $881-906$.

2002b. Public policy for health care. In Handbook of public economics. Vol. 4, ed. Alan Auerbach and Martin Feldstein, 2143-2243. Amsterdam: Elsevier.

Cutler, David, and Mark McClellan. 1998. What is technological change? In Inquiries in the economics of aging, ed. David Wise, 51-81. Chicago: University of Chicago Press.

Cutler, David, and Richard Zeckhauser. 2000. The anatomy of health insurance. In Handbook of health economics. Vol. IA, ed. Anthony Culyer and Joseph P. Newhouse, 563-643. Amsterdam: Elsevier.

DiMasi, Joseph A., Ronald W. Hansen, and Henry G. Grabowski. 2003. Cost of innovation in the pharmaceutical industry. Journal of Health Economics 22 (2); $151-85$.

Enthoven, Alain C. 1993. The history and principles of managed competition. Health Affairs 12 (1): 24-48.

Evans, Robert G. 2002. Raising the money: Options, consequences, and objectives for financing health care in Canada. Commission on the Future of Health Care in Canada. Discussion Paper no. 27. Ottawa: Commission on the Future of Health Care in Canada.

Feldstein, Martin S. 1973. The welfare loss of excess health insurance. Journal of Political Economy 81 (2): 251-58.

Getzen, Thomas. 2000. Health care is an individual necessity and a national luxury: Applying multilevel decision models to the analysis of health care expenditures. Journal of Health Economics 19 (2): 259-70.

Glied, Sherry. 2000. Managed care. In Handbook of health economics. Vol. IA, ed. Anthony Culyer and Joseph P. Newhouse, 709-27. Amsterdam: Elsevier.

Gruber, Jonathan. 1994. The incidence of mandated maternity benefits. American Economic Review 84 (3): 622-41.

Hackbarth, Glenn M. 2003. Medicare cost-sharing and supplemental insurance. Statement before the Subcommittee on Health, Committee on Ways and Means, U.S. House of Representatives. 107th Cong., 2nd sess., May 1, 2003.

McClellan, Mark. 1997. Hospital reimbursement incentives: An empirical analysis. Journal of Economic Management and Strategy 6 (1): 91-128.

McGuire, Thomas. 2000. Physician agency. In Handbook of health economics. Vol. 1 A, ed. Anthony Culyer and Joseph P. Newhouse. Amsterdam: Elsevier.

Miller, Robert H., and Harold S. Luft. 1997. Does managed care lead to better or worse quality of care? Health Affairs 16(5): 7-25.

Newhouse, Joseph P. 1993. Free for all: Lessons from the Rand Health Insurance Experiment. Cambridge, MA: Harvard University Press. 
Organization for Economic Cooperation and Development (OECD). 2002. OECD health data. CD-ROM.

Reinhardt, Uwe. 2004. The Swiss health system: Regulated competition without managed care. JAMA, 292 (10): 1227-31.

Summers, Lawrence. 1989. Some simple economics of mandated benefits. American Economic Review 79 (2): 177-83. 
This Page Intentionally Left Blank 